\title{
Computer-Assisted Instruction (CAI), Virtual Patients (VP), and Human Patient Simulation (HPS) in Medical Education Based on Gagne's Educational Design Pattern
}

\author{
Hossein Torbatinezhad $^{1^{*}}$, Hossein Amani ${ }^{2}$ \\ 1. Department of Educational Sciences, Farhangian University, Tehran, Iran. \\ 2. Golestan Research Center of Gastroenterology and Hepatology, Golestan University of Medical Sciences, Gorgan, \\ Iran.
}

Article Type:

Review Article

\section{Article History:}

Received: 25 Jun. 2017

Revised: 24 Jun. 2018

Accepted: 11 Jul. 2018

\section{*Correspondence:}

Hossein Torbatinezhad,

Department of

Educational

Sciences, Farhangian

University, Tehran,

Iran

h_torbatinezhad@yaho o.com

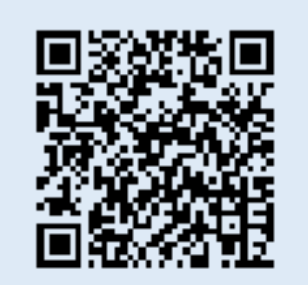

\begin{abstract}
Background and objectives: Educational technology is widely used in all parts of medical education. The use and application of common educational technologies and adoption of educational design patterns in medical sciences education can greatly help in medical simulations, training, and improving of clinical skills of nurses and medical students. The aim of this research was to study computer-assisted instruction, virtual patients, and human patient simulation in medical science education based on Gagne's educational design pattern.
\end{abstract}

Methods: The research methodology in this paper was a review-article of applied type, which helps the education designer in the field of medical education to choose the most suitable educational technologies in medical science education to achieve their desired goals by considering the advantages and disadvantages of computer-assisted instruction, virtual patients, and human patient simulation.

Results: In this article, we first reviewed the educational technology and common technologies in medical education and its advantages and disadvantages as well as the most appropriate educational technology to achieve the needed goals. We then described two multimedia (Computer-Assisted Instruction and Virtual Patients) and educational models for virtual patients as well as two simulators (virtual patient and human patient simulation). Subsequently, we explored the educational design and its patterns (including Ganja, Watson, Merrill, Reigeluth, Asher, Camp, and Siemens) and selected the best pattern (Gagne's pattern) according to the learning theories and research background. Finally, the three approaches mentioned in this article (computer-assisted instruction, virtual patients, human patient simulation) were designed based on the Gagne's model.

Conclusion: Based on the results, one can conclude that the computer-assisted instruction, virtual patients, and human patient simulation based on the Gagne's educational design model can help medical education instructors in training communication skills, clinical skills, and skills of obtaining medical history from the patient as well as problem-solving skills, knowledge acquisition, and critical thinking. They can also help the educational designer in the field of medical education to select the most suitable educational technologies in medical science education due to the best educational model of virtual patients and the Meyer educational media principles and simulation-based learning-educational theories tailored to the goals and content of medical education courses. Therapies for autoimmune disorders such as SLE.

Keywords: Computer-Assisted Instruction, Medical Science Education, Virtual Patients, Human Patient Simulation, Educational Design

Copyright $($ C 2018, Jorjani Biomedicine Journal has published this work as an open access article under the terms of the Creative Commons Attribution License (http://creativecommons.org/licenses/by-nc/4.0/) which permits noncommercial uses of the work while it is properly cited. 


\section{Introduction}

Modern educational technology can employ the decision-making processes of learners and provide realistic answers to generate individual learning experiences. Also, common educational technology in medical sciences (computer-assisted instruction, virtual patients, and human patient simulation) can provide a unique opportunity for students in medical education environments to develop their competencies (knowledge, skills, attitude) in patient care and an appropriate tool for teaching communication skills, clinical skills, and skills for obtaining medical history from patients. Computer-Assisted Instruction (CAI) plays a vital role in the development of medical education along with numerous benefits mentioned in studies. Although different software and applications are used in surgical training programs but the use of computer-assisted instruction is still unclear. Problem-based learning (PBL) emphasizes the application of knowledge and skills in problem solving that are considered by various medical schools. It is believed that the use of computer simulation is effective in promoting learning method based on problem-solving approach and can enhance the students' experience in dealing with patients (1).

Virtual patients are a kind of e-learning resources in which the learner plays the role of his health care measures, interactive diagnosis, and behavior and his patient. The main advantage of virtual patients is primarily to promote clinical reasoning skills. Human patient simulation is a type of simulationbased learning that provides a unique opportunity for students to apply what they have learned and allows them to practice their problem solving skills (2). Virtual patients are a form of computer-assisted education used in various medical disciplines. Virtual patients can be utilized as a preparation tool for assisting clinical judgment as well as learning about the patients' treatment procedures. If cleverly used, virtual patients they can improve medical education (3).

In a study, Cook et al. defined virtual patients as a type of special computerized programs simulating clinical scenarios and real life, in which, learners impersonate a role of health care providers to gain the patients' medical history, perform a physical examination, and make diagnostic and therapeutic decisions (4).The results of research by Cameron (2005) suggested that computer-assisted instruction can develop the training structure, simulation of clinical situations, creation of training conditions, and facilitating the study of medical students (8). The results of Amy study (2008) showed that the use of human patient simulation improves the knowledge and ability in students to solve the patients' treatment problems and increases the students' self-esteem (7). The results obtained by Issenberg research (2005) revealed that the use of human patient simulation improves the acquisition of critical thinking and knowledge and leads to increased students' satisfaction with learning (9).

It was shown in the results of a research by Shariat et al. (2007) that training by using virtual patients is effective in increasing skills in taking patients' history, while it showed no significant impact on other aspects of clinical skills (1). According to Deladisma (2007) results, virtual patients can complement the curriculum available in medical faculties (6). Horstmann (2009) data demonstrated that virtual patients can serve as a useful tool in undergraduate baccalaureate education at the 
integrated teaching approach (5). Findings of Lehman (2013) indicated that there is a general acceptance among students and professors regarding integrated learning approach and virtual patients provide a good cognitive tool for teaching skills (2). Forsberg et al. (2016) conducted a research entitled as "Assessment of Advances in Clinical Reasoning through Virtual Patients: An Exploratory Study". There findings provided a clear breakthrough in the ability of students' clinical reasoning. After initial evaluations, the students described a sense of skepticism. But in the second assessment, awareness of clinical reasoning had been improved and students showed more confidence in knowing how to resolve the virtual patients' cases and situations. Eventually, the self-efficacy of students was described in the final assessment (3).

Since no extensive research has been done on the use and application of common educational technologies in medical science in Iran and as a systematic approach is essential for educational design in the medical science, thus, we decided to study three common educational technologies in medical science education (computer-assisted instruction, virtual patients, and human patient simulation) based on Gagne's Educational Design Pattern, which can help the medical education instructors to train communication skills, clinical skills, and skills of taking patients' history as well as problem solving skills, acquiring knowledge, and critical thinking. Therefore, this study aimed to examine computer-assisted instruction, virtual patients, and human patient simulation in medical science education based on Gagne's educational design pattern.

\section{Materials and Methods}

The research methodology was a review article approach, which was performed by searching articles related to the subject and considering key words (Medical Education, Computer Aided Instruction (CAI), Virtual Patients (VP), Human Patient Simulation (HPS), Instructional Design) in specialized DOAJ, pubMed, JAMA, Scopus, Sciencedirect, Google Scholar databases electronically. Then, the search was continued manually through published articles in these databases. A total of 127 articles were found, of which, 53 articles related to the subject were selected, collected, studied, and categorized. Then, the content was and extracted from them. The articles covered four areas of medical education, including computer-assisted instruction, virtual patients, human patient simulation, and Gagne's educational design pattern between 1990 and 2016. In this paper, we examined educational technology and common technologies in medical education and its advantages and disadvantages and the most appropriate educational technology to achieve the goals. In the sequel, we described two multimedia (Computer-Assisted Instruction and Virtual Patients) and training models for virtual patients and two simulators (virtual patient and human patient simulation). Finally, we studied the educational design and its patterns and selected the best model. Then, we designed three approaches mentioned in this article (computer-assisted instruction, virtual patients, human patient simulation) based on Gagne's model. This was an applied research and computer-assisted instruction, virtual patients, human patient simulation based on Gagne's educational design model can help medical education instructors to teach communication skills, clinical skills, and skills for obtaining patients' history as well as problem-solving skills, acquisition of knowledge, and critical thinking with a systematic approach. In addition, considering their advantages and disadvantages, they can 
choose the most suitable educational technologies in medical science education to achieve the pre-planned goals.

\section{Results}

The articles listed in the findings section are a combination of educational technology field and the field of medical education. Educational technology is widely used in all parts of medical education. The subject of information technology and e-learning is one of the common topics discussed in the fields of educational technology and medical education. Virtual patients and human patient simulations are a kind of e-learning resources, in which, the learner plays the role of health care and interactivity of his behavior and his patient. Since very limited studies have been conducted on this topic in Iran, most articles extracted in the findings section are foreign articles, most of which are original and experimental research papers.

Analyzing the results, we first examined the educational technology and common technologies used in medical education and their advantages and disadvantages and the most appropriate educational technology needed to achieve the goals. We then described two multimedia (computer-assisted instruction, and virtual patients) and educational models for virtual patients and two simulators (virtual patient and human patient simulation). Finally, we evaluated the educational design and its patterns (including Ganja, Watson, Merrill, Reigeluth, Asher, Camp, and Siemens models) and selected the best model (Ganja pattern) according to learning theories and research background. Accordingly, three approaches mentioned in this article (computer-assisted instruction, and virtual patients) were designed based on the Ganja model.

\section{Educational Technology}

Educational technology provides several benefits for educators and instructors in areas of learning concepts, activating, individual learning, and working automatically. Technology can reproduce a purpose or concept in a form and structure that may have been created by designers so that the user will use it for educational purposes in an ideal mode. These benefits have been clearly described in the simulation technology, which can be generated by computer-based models in the real-life process. Exploring in realistic environments provides many benefits for learners, including creating opportunities for pure practice and critical events, creating safe and controlled environments that limit the risk of disease, facilitating the visualization process, and the creation of valid intellectual domains and evaluations. Assessment and evaluation of learners' behaviors and their outcomes have been documented in these environments. Modern educational technology can use the decision-making processes of learners and provided realistic answers to produce individual learning experiences. Educational technology coordinates the features of considerable activities of adult learner with the learner's learning (11).

\section{Common Technologies in Medical Education}

There are several frameworks that can be used in describing and categorizing educational technology applications. We considered three broad categories here that are based on the prevailing benefits of medical education. Although these applications overlap with technology components of educational facilities but differ 
from them based on the feature of thinking independently.

\section{Computer-Assisted Instruction (CAI)}

Computer-assisted instruction programs play an essential role in replacing many educational instructors. These programs can use Internet technology (web-based learning) and involve a range of independent applications or online materials (12).

\section{Virtual Patients (VP)}

Virtual patients are a special type of computer-based programs, which are realistic simulations of clinical texts. Learners imitate the role of health care providers in acquiring a patient's history, do medical examinations, diagnose, and eventually make the necessary therapeutic decisions (13).

\section{Human Patient Simulation (HPS)}

The use of mannequins and models to simulate patient care environments is done for educational comparison or assessment and evaluation. The tools in this set include taskbased learners that simulate specific practical assignments such as virtual realistic colonoscopy learners (8).

Table 1. Advantages and Disadvantages of Multiple Educational Technologies $(8,12,13)$

\begin{tabular}{|c|c|c|}
\hline $\begin{array}{l}\text { Type of } \\
\text { Instruction }\end{array}$ & Advantages & Disadvantages \\
\hline $\begin{array}{l}\text { Computer- } \\
\text { Assisted } \\
\text { Instruction }\end{array}$ & $\begin{array}{l}\text { Useful to visualize complex processes } \\
\text { Independent discovery of complex phenomena } \\
\text { Relatively low production costs }\end{array}$ & $\begin{array}{l}\text { Limiting physical interactions } \\
\text { Reducing credibility and accuracy }\end{array}$ \\
\hline $\begin{array}{l}\text { Virtual } \\
\text { Patients }\end{array}$ & $\begin{array}{l}\text { Encompassing multiple dimensions of clinical exposures } \\
\text { Caring in longitudinal and multidisciplinary studies } \\
\text { Easy admission } \\
\text { Quickly turning into the desired situation }\end{array}$ & $\begin{array}{l}\text { Limiting physical interactions } \\
\text { Reducing credibility and accuracy } \\
\text { High production costs }\end{array}$ \\
\hline $\begin{array}{l}\text { Human } \\
\text { Patient } \\
\text { Simulation }\end{array}$ & $\begin{array}{l}\text { Active and immersive experiences } \\
\text { Involving emotion and sensory learning } \\
\text { Developing clinical thinking and establishing communication } \\
\text { Reviving basic sciences in clinical content }\end{array}$ & $\begin{array}{l}\text { Costly and specific requirements } \\
\text { Limited to the simulator and } \\
\text { personnel access } \\
\text { Technical review limitations }\end{array}$ \\
\hline
\end{tabular}

\section{Effective Programs of Matching \\ Educational Approaches with Educational Objectives}

Medical education environments include a combination of cognitive, perceptual, and psychomotor educational goals. Each type of objectives may be achieved through the use of at least one educational technology. Table 2 shows how different technologies may be used based on a combination of available research, perceived resources, and technical abilities. 
Table 2. The Most Suitable Educational Technologies for Achieving Special Educational Goals $(8,12,13)$

\begin{tabular}{lll}
\hline Educational Goal & Suggested Educational Technology \\
- & Facilitating Basic Knowledge \\
Acquisition & $\begin{array}{l}\text { Computer-assisted instruction } \\
\text { Virtual patients }\end{array}$ \\
- Decision-making Improvement & $\begin{array}{l}\text { Computer-assisted instruction } \\
\text { Virtual patients } \\
\text { Human patient simulation }\end{array}$ \\
- & Facilitating Perceptional & $\begin{array}{l}\text { Computer-assisted instruction } \\
\text { Virtual patients }\end{array}$ \\
- Variables & Improving Coordination Skills & $\begin{array}{l}\text { Human patient simulation } \\
\text { Task instructors }\end{array}$ \\
- & Special Practice / Clinical Event & $\begin{array}{l}\text { Virtual patients } \\
\text { Human patient simulation }\end{array}$ \\
- & Organizing Group Training & Human patient simulation \\
- & Improving Psycho-Motor Skills & Task instructors \\
\hline
\end{tabular}

Multimedia (Computer- Assisted Instruction and Virtual Patients)

Virtual patients are a kind of e-learning resources in which the learner plays the role of health care and interactivity of his behavior and his patient. E-learning with virtual patients is a process in which a user-student learns through simulation cases and plays the role of a physician in treating patients. In general, e-learning has proven to be an effective and useful educational tool in medical education (14), including areas such as radiology and skin (15). E-learning has turned into standard treatment routes like medical emergencies (16).

There are several different definitions for the concept of virtual patients that are often used vaguely (17). The definition of virtual patients in this paper involves an interactive computerized simulation in the real and clinical life with the goals of health and medical instruction and medical students' education. Virtual patients have been used in medical education in the late 1960's. This educational tool has been further developed ever since (18).
The approach of virtual patients is a wellknown and successful method for simulating the patient's realistic state with a high degree of loyalty in various types of medical, dentistry and nursing courses (19).

Virtual patients' approaches have provided the possibility of multi-media embedding, including audio and video clips to illustrate the methods to the patients. The main advantage of virtual patients' approach is primarily to promote clinical reasoning skills. The virtual patients' technology can be used to evaluate students' skills. Hubal et al. believe that using case studies, including all three types of patients (real, simulation, and virtual), is an appropriate method for evaluating students' skills. In the United States, 94 medical schools use simulated virtual patients in their educational programs and 26 medical schools participate in sharing resources, standard tools, and effective implementation of simulation programs (20). The use of virtual patients allows students to develop their competencies (knowledge, skills, attitudes) in providing care to patients (21). 
Table 3. Educational Models for Virtual Patients (22)

\begin{tabular}{ll}
\hline $\begin{array}{l}\text { Self-Leading } \\
\text { Learning }\end{array}$ & $\begin{array}{l}\text { Make simple cases available to individual learners and complete them with limited } \\
\text { interactions associated with the author, training instructor, and experts. }\end{array}$ \\
$\begin{array}{l}\text { Problem-Based } \\
\text { Learning }\end{array}$ & $\begin{array}{l}\text { Forming small educational groups with facilitators where students have access to } \\
\text { virtual patients as a group and are involved with them. }\end{array}$ \\
$\begin{array}{l}\text { Distance (Remote) } \\
\text { Learning }\end{array}$ & $\begin{array}{l}\text { Learners have independent access to online virtual patients, but remotely control the } \\
\text { access to the experts simultaneously (conversation) or non-simultaneously (discussion } \\
\text { page or email). }\end{array}$ \\
Blended Learning & $\begin{array}{l}\text { - Learners are continuously involved with a virtual patient with an educational support } \\
\text { instruction, discussions in small groups or other simulator actions. }\end{array}$ \\
$\begin{array}{l}\text { Measurement and } \\
\text { Evaluation }\end{array}$ & $\begin{array}{l}\text { Learners devote a virtual patient to developmental evaluation or summative (final) } \\
\text { assessment of skills. }\end{array}$ \\
\hline
\end{tabular}

When designing or purchasing educational technology resources, which are multimedia elements, the participants should pay attention to the selection, sequencing, and presenting of information. Certain elements can include high or low recognition of learning such as the style of providing information and the proportionality of learning materials.
Therefore, one challenge in effective educational design is to produce applications, involving those features that improve learning while avoiding misleading elements that may lead to learning deviations. Richard Mayer suggests Ten Educational Media Principles to guide educational instructors in using multimedia elements in the applications for educational activities. Remembering these principles, the following should be pursued (23).

Table 4. Ten Mayer Education Media Principles for Medical Instructors (23)

\begin{tabular}{|c|c|}
\hline Coherence Principle & Avoiding the inclusion of unrelated words, images, and sounds \\
\hline $\begin{array}{l}\text { Pre-Training } \\
\text { Principle }\end{array}$ & $\begin{array}{l}\text { - Ensuring the process of prior knowledge of students about their names and } \\
\text { characteristics of the main concepts }\end{array}$ \\
\hline $\begin{array}{l}\text { Spatial Contiguity } \\
\text { Principle }\end{array}$ & - Presenting related words and images in close proximity to each other \\
\hline $\begin{array}{l}\text { Temporal } \\
\text { Contiguity Principle }\end{array}$ & $\begin{array}{l}\text { - Presenting related words and images at the same time instead of presenting them } \\
\text { sequentially }\end{array}$ \\
\hline Signaling Principle & - Highlighting important words \\
\hline $\begin{array}{l}\text { Redundancy } \\
\text { Principle }\end{array}$ & - Matching animation (graphics) and text voice without displaying text on the screen \\
\hline Voice Principle & $\begin{array}{l}\text { - Using someone to narrate the text on the voice generated by the simulator without } \\
\text { accent }\end{array}$ \\
\hline $\begin{array}{l}\text { Personalization } \\
\text { Principle }\end{array}$ & - The use of conversation style instead of using official styles to narrates words \\
\hline $\begin{array}{l}\text { Segmenting } \\
\text { Principle }\end{array}$ & $\begin{array}{l}\text { - Presenting animated with text in the learner's motion section instead of the } \\
\text { continuous unit }\end{array}$ \\
\hline Modality Principle & $\begin{array}{l}\text { - Combining animation and text together instead of association of animation with } \\
\text { on-screen text }\end{array}$ \\
\hline
\end{tabular}




\section{Simulators (Virtual Patient, Human Patient} Simulation)

Human patient simulation is a type of simulation-based learning, which provides a unique opportunity for students to apply what they have learned and allows them to practice problem-solving skills. Through involving in human patient simulations, students grow their self-confidence. Human patient simulation is a new available tool with high loyalty for medical instructors to use mannequins for simulating medical problems, which enables students to integrate their knowledge through experimental learning and optimizing patient safety (7).

The human patient simulation is a form of experiential learning, in which, the learner forms the knowledge structures by linking the new information with the previous knowledge. The facts, methods, concepts and principles can be taught in a more realistic context. The teamwork skills such as communications, leadership and resource management, which cannot be taught well through standard educational tools, can be effectively trained in a human patient simulation environment (8).

The number of specialized medical training programs that use simulators with high loyalty is growing. These simulators are highly different in how to use the technology, how to engage with educational instructors and the area where each simulator activities are included in the curriculum. In the latest review, 10 features of high loyalty to reality, including anesthetics, cardiovascular and surgical procedures, have been defined. Some of these features are related to the Ericsson Performance Model in professional performance in terms of mastery. Although this list of studies is derived in the area of simulators with high loyalty but many of its principles may be applied to virtual patients (24).

Table 5. Specialized programs in medical education that use high-loyal simulators (24)

\begin{tabular}{ll}
\hline Feedback & $\begin{array}{l}\text { Effective and constructive feedback from performance is one of the most important } \\
\text { features of simulation-based education in medical education and the most important } \\
\text { factor in ensuring the transfer of skills to the patient. It reduces the speed of skills } \\
\text { decline over time and forgetting them. }\end{array}$ \\
Repetitive action & $\begin{array}{l}\text { It provides opportunities for learners to engage with the subject, repeat the practice } \\
\text { aimed at improving the skills, which is an essential learning feature to prevent } \\
\text { stagnant learning. However, it's essential to ensure the transfer of skills actual } \\
\text { patients. }\end{array}$ \\
Syllabus integration & $\begin{array}{l}\text { The simulation-based instruction should be extraordinary and amazing. However, it } \\
\text { should be built according to the training and timing requirements of learners and } \\
\text { needs to be evaluated according to the methods requested by them as well. }\end{array}$ \\
Difficulty & level $\begin{array}{l}\text { When learners achieve opportunities to engage in medical skill exercises at a } \\
\text { difficulty level spectrum, the learning will be facilitated. Helping learners in } \\
\text { mastering skills at levels of increasing difficulty can decrease the skills decline over } \\
\text { time. }\end{array}$ \\
Multiple learning & $\begin{array}{l}\text { Ideally, simulators should employ multiple strategies for training, which include } \\
\text { large groups (such as lectures), helping small groups (such as tutorials) and both } \\
\text { strategies }\end{array}$ \\
individual learning and small groups without instructional educators. \\
Recording clinical
\end{tabular}




\begin{tabular}{ll}
\hline \hline environment & $\begin{array}{l}\text { of patients with causing no side effects. This happens while educational instructors } \\
\text { can focus on learners more than the patients. }\end{array}$ \\
Individual learning & $\begin{array}{l}\text { The learners' opportunities for reproduction, use of educational experiences in each } \\
\text { of the areas where learners participate actively and are not as inactive viewers is a } \\
\text { general feature of these simulators. }\end{array}$ \\
$\begin{array}{l}\text { Determining the - If the result is determined and opportunities are provided for the learners' previous } \\
\text { results or criteria } \\
\text { educational background level to practice with the simulator, the learners are more } \\
\text { likely to master key and important skills. }\end{array}$ \\
$\begin{array}{l}\text { The validity and } \\
\text { simulator of the }\end{array}$
\end{tabular}

\section{Concept of Educational Designing}

Educational designing is a systematic process of planning all events to facilitate learning (25). Educational design is known as a science and also as an art (26). In fact, the educational design is a framework for the creative design process and ensuring that the learners' needs are met. The meaning of educational design depends on the individual's background and theory (27). The educational design process involves independent stages, including learner analysis, content and goals, designing goals, selecting strategies and evaluation tools, producing training materials, assessing the learner's performance, and measuring the effectiveness of the educational design (28). Educational design provides a framework for systematic design, the development and adaptation of education based on the learners' needs and education content. Through the educational design process, teachers assess the needs of learners, draw the purpose of the course, design and the educational content make assessments (29).

A set of key elements are involved in this systematic process, which include identifying educational issues and problems, studying the learner's characteristics, identifying the content of subject, determining educational objectives, and content sequences in each training unit for rational learning, determining educational strategies, defining educational messages, developing education, providing
Evaluation tools and selecting resources to support educational and learning activities. The components of the educational design, separately, are as follows: The basic design of a rational, logical, and sequential process for solving problems, based on which, the design process should be considered as a problemsolving process (30).

When talking about educational design, noting that systematic training consists of various components such as goals, content and so on with their own input, process, and output, it is more accurate to use designing an educational system instead. System, as Clark (2006) states, is a set of concepts and components working together to perform a specific task to accomplish a common goal.

Gustafson \& Branch argue that educational design has special features nowadays, which should be observed in all educational efforts. These features include:

- Educational design is learner-centered.

- Educational design is purpose-oriented.

- Educational design focuses on performance in the real world.

- Educational design emphasizes the consequences that are measured by a reliable and valuable method.

- Educational design is experimental.

- Educational design is a typical team effort (31).

In short, in summing up the discussion of the concept of educational design, one can state that designing is an activity aimed at 
solving a problem to fulfill human needs and education encompasses everything that facilitates the realization of learning, which consists of various components such as goals, form of presentation, grouping, etc. Accordingly, the design of the education system is the process of analyzing, designing, producing, implementing, and evaluating a complete education system.

\section{Educational Design Models}

Since there are many results, conditions and methods in a variety of educational situations, thus, the educational design patterns and models also appear to be very diverse. Chen (2008) suggests that there are currently over 100 educational design models, each of which, has certain capabilities. In the following, we introduced the most famous educational design models (32).

\section{Robert Gagne and Briggs Model}

This model was presented in the 1970's based on the importance of educational events in the training process by Gagne and Briggs. In this design model, 9 educational events should be considered:

1. Drawing the learner's attention

2. Describing learning objectives to the learner

3. Recalling previous teachings

4. Providing educational materials

5. Providing learning guidance

6. Performance test

7. Providing feedback

8. Performance assessment

9. Encouraging and facilitating reminding and transfer (33).

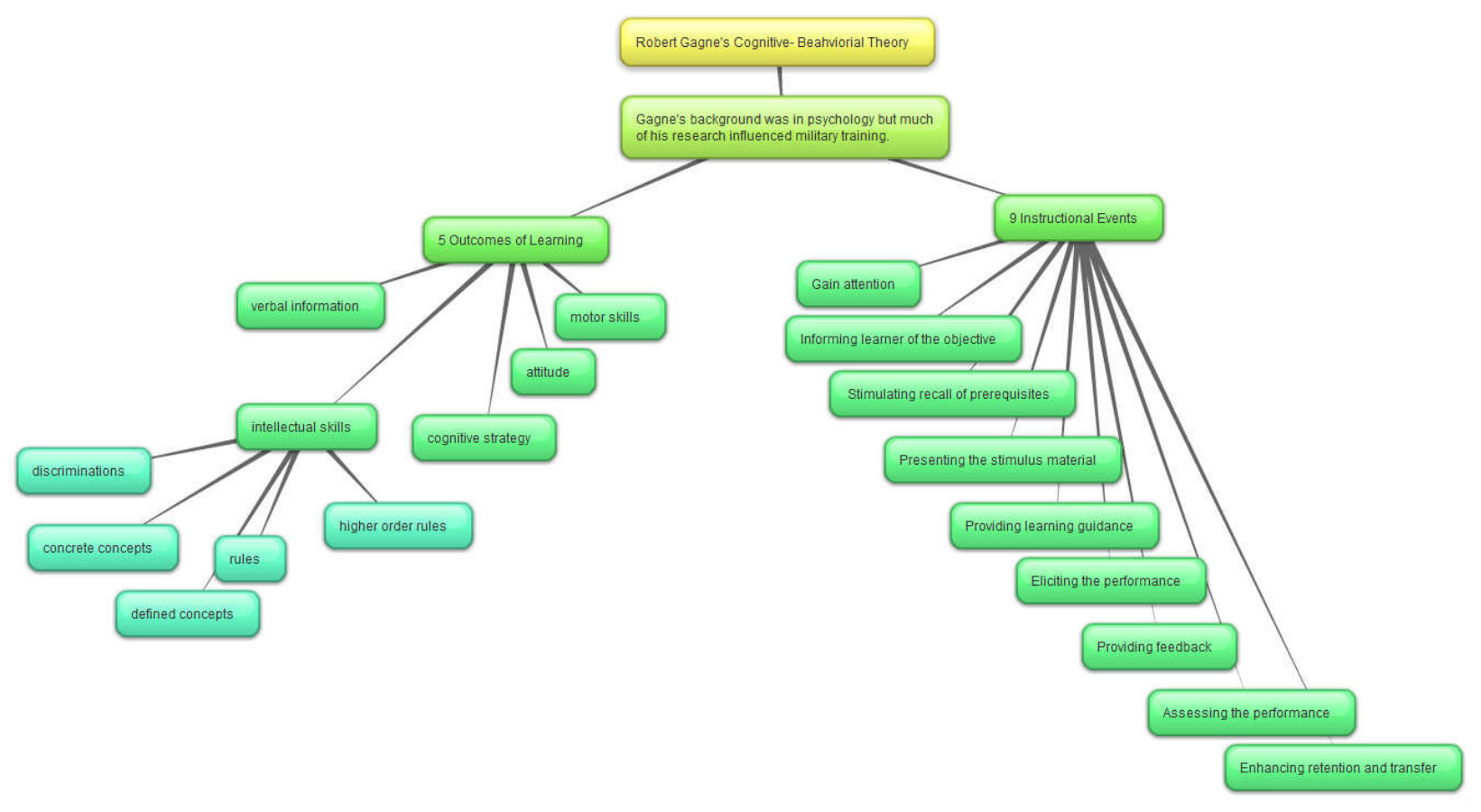

Figure 1. Gagne's Educational Design Model (27) 


\section{Watson Model}

The model was designed in 1975 at Florida State University in the United States, which was used for military training. Afterward, some changes were made by Russell Watson in tis steps at the International Individual Education Congress; but its five steps were not changed. This model is used for both individual training and common education. In addition, this model has been used in the design of global learning and e-learning design in recent years. The five components of this model are as follows:

1. Analysis

2. Design

3. Development

4. Implementation

5. Evaluation (34).

\section{David Merrill Model}

This model was presented by Merrill in 1981. The components of this model and its stages are as follows:

1. Determining the characteristics of learners

2. Determining the type of expected performance

3. Explaining the types of initial presentation

4. Determining the types of secondary presentation

5. Observing the principles of separation, diversity, match-making and difficulty level (35)

\section{Reigeluth Model}

This model was introduced in 1983 by Reigeluth. Based on this model, mostly used for organizing educational topics, he provides a perspective on the main subject of educational content in terms of training preliminaries and then emphasizes its description and expansion. In recent years with the advent of modern technologies and the transformation of traditional educational and learning processes, Reigeluth has introduced new technology-based paradigms and has accordingly developed its previous model. In recent years, he has also developed and provided a model called "A model for designing technology systems and a computer-based simulations design model. This model contains the following stages:

1. Simple to complex order

2. An order of presenting learning prerequisites

3. Summarization

4. Composition

5. Allegory (36)

\section{John Keller Model}

This model, known as the motivational design model of education, was presented by Keller in 1983. The components of this model are as follows:

1. Attention

2. Relationship

3. Trust

4. Satisfaction

Keller has developed his original model in recent years so that this model is used in the design of electronic learning to enhance motivation as well (37). 


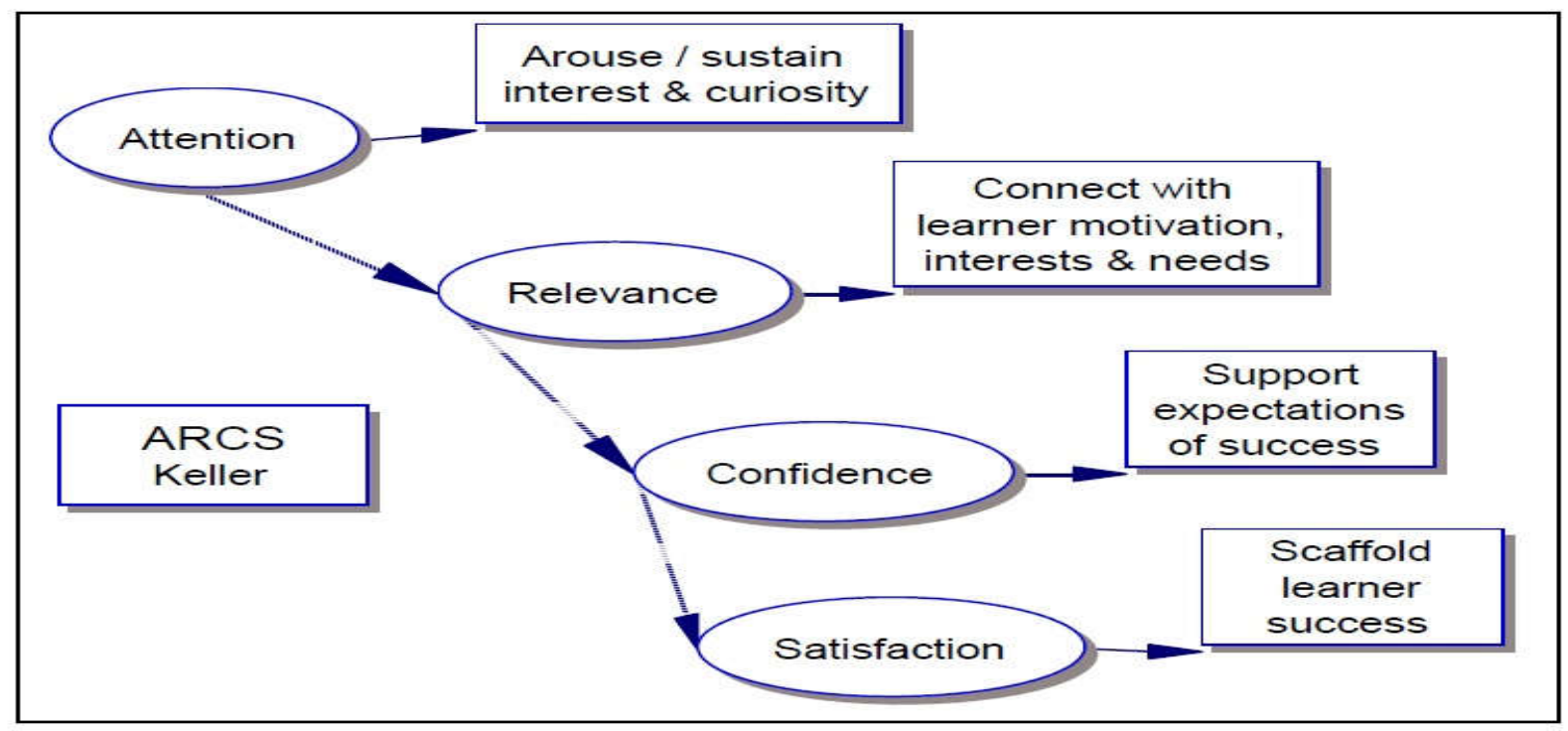

Figure 2. Keller ARCS Motivational Model (27)

\section{Assure Model}

This model was presented by Malanda, Russell, and Hennich in 1997. The components of this model are as follows:

1. Analysis of learners' features

2. Determining the objectives

3. Selection of methods, media and materials

4. The use of media and materials

5. The learner's engagement

6. Evaluation and revision (Hennich et al., 1999)

This model is used to design learning centers (38).

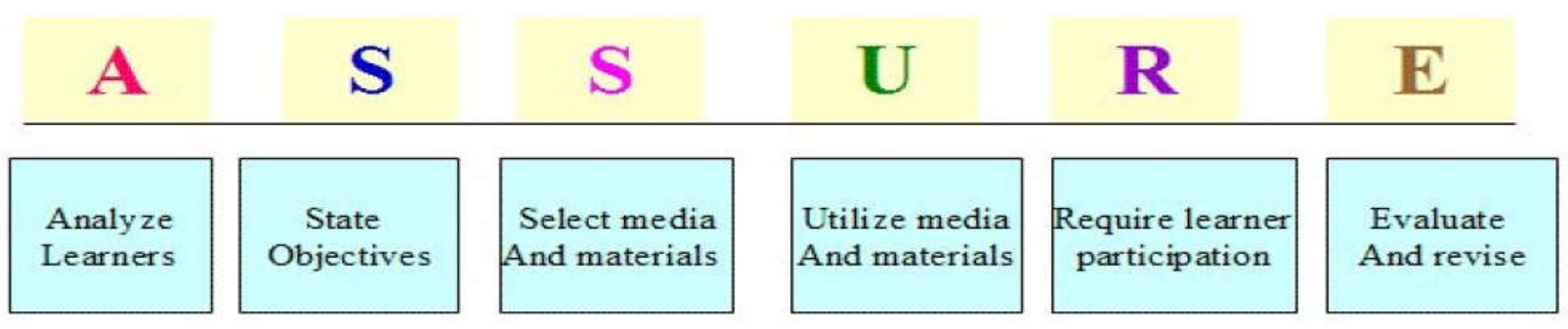

Figure 3. ASSURE Model (27) 
Ross, and Camp in 2004 under the title of "Effective Education Design Model". The components of this model are shown in the following figure (39).

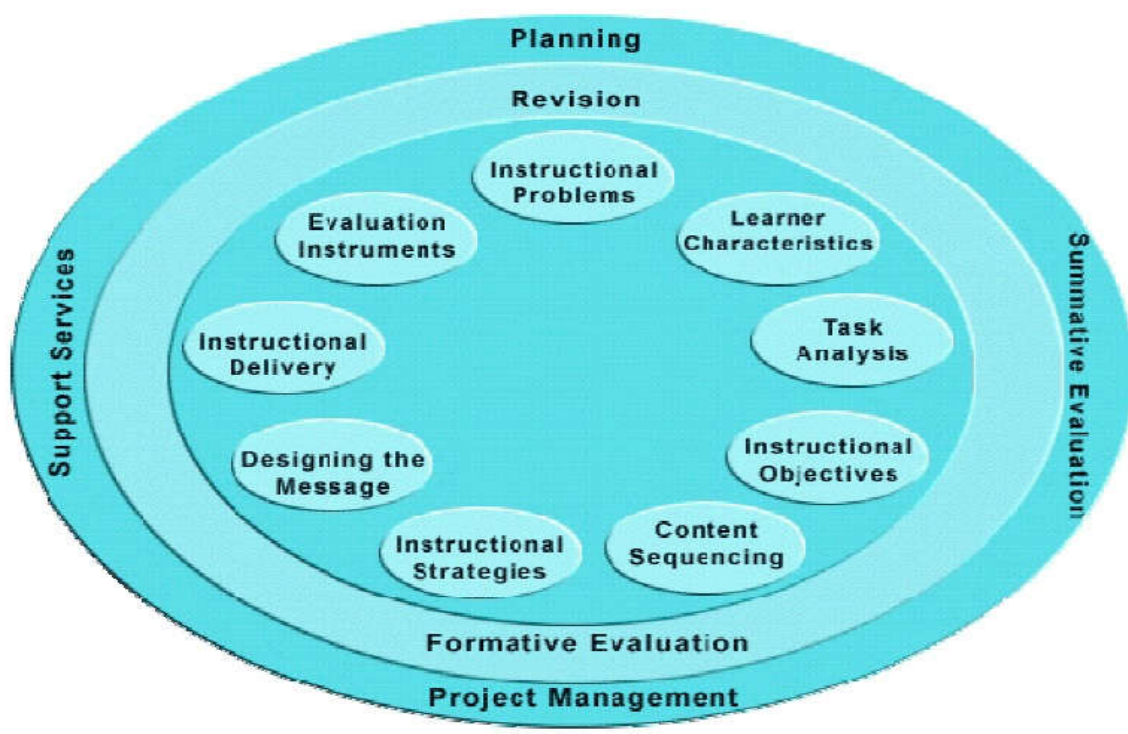

Figure 4. Camp Model (27)

\section{Siemens Model}

This design model was first introduced in 2005 by Siemens. The components of this model are as follows:

1. Invention and innovation

2. Research

3. Implementation

4. Systemizing

This model is designed based on the Theory of Connectivism. The theory of connectivism was first proposed and presented by George Siemens in 2004. According to Siemens, connectivism is the learning theory for the digital age, in which, technological tools and the rapid growth of knowledge provide a ground of complex, extensive, and up-to-date communications. In such conditions, the learners acquire the ability to invent, innovate, and produce content individually and collectively by benefiting from global interactions and access to the specialists (40).
Considering the basic features of the models mentioned, some of their strengths are as the following:

1. Attention to education as a systematic process

2. Making the education purposeful and attempting for its effectiveness

3. Providing a framework and guidance to the teacher to implement the training

4. Paying attention to the components of analysis, design, implementation and evaluation in the training process

5. Presentation of the perspective and attention to the organization issue in providing educational topics

6. Attention to motivation as a key element in education

7. Attention to the characteristics of learners and the adaptation of other elements of learning with them

8. Attention to continuous review and improvement in the training process

9. Attention to the new paradigms of change in the educational system 
10. Attention to the necessities and requirements of the digital age

Despite numerous advantages of these models and other educational design models and learning environments, some of which are listed above, they have also some weaknesses that some are mentioned in the table below.

Table 6. Weaknesses of Educational Design Models and Learning Environments Based on Two Criteria of Type of Approach and Attention to 12 Key Elements of the Comprehensive Learning Design Process and Learning Environments

\begin{tabular}{|c|c|c|c|}
\hline Row & Design model & $\begin{array}{l}\text { The type of design } \\
\text { model approach }\end{array}$ & $\begin{array}{l}\text { The amount of attention to the basic elements } \\
\text { of comprehensive educational design process }\end{array}$ \\
\hline 1 & Gagne & Independent & 2 Educational Elements \\
\hline 2 & Watson & Independent & 4 Educational Elements \\
\hline 3 & Merrill & Independent & 2 Educational Elements \\
\hline 4 & Reigeluth & Independent & 3 Educational Elements \\
\hline 5 & Keller & Independent & 1 Educational Element \\
\hline 6 & $\begin{array}{l}\text { Malanda, Russell, and } \\
\text { Hennich }\end{array}$ & Independent & 4 Educational Elements \\
\hline 7 & $\begin{array}{l}\text { Morrison, Ross, and } \\
\text { Camp }\end{array}$ & Independent & 8 Educational Elements \\
\hline 8 & Siemens & Independent & 0 Educational Element \\
\hline
\end{tabular}

\section{Choosing the Best Educational Design Model}

Out of the eight proposed models, the Gagne's model was selected as the basis of research for the following reasons:

1. The Gagne's educational design model is one of the cognitive theory models, which works in teaching critical thinking and clinical thinking, self-centered learning and, consequently, lifelong learning better than the two behaviorism and constructivism approaches $(41,42)$.

2. The Gagne's model can help medical education instructors to train communication skills, clinical skills and skills for taking the patient's history. It can also be useful in problem solving skills, acquisition of knowledge, and critical thinking (43).

3. The results of several studies show that the Gagne's model is more efficient compared to other models:

Khadjovy, Rostami and Eshagh (2011) state in a research entitled as "How can we use the Gagne's educational design model to teach psycho-motor skills?" that the theory provides information with tremendous value for teachers. The application of the ninestage Gagne's model is a very suitable method to ensure an effective and systematic learning program since it provides a framework for curricula and a comprehensive approach to education (43). 
In a research entitled as "Comparison of the effect and effectiveness of two educational methods of geometric shapes concepts in mentally retarded students", Unal and Ozmen (2008) showed that Gagne's model has been more effective than Merrill's model in acquisition and maintaining the concept on both groups of participants. Although the impacts of both models on its continuity of the participants were not significantly different but the results also showed that Gagne's model requires less teaching time than the Merrill model (44). During a research entitled as "The impact of Gagne Gary and Briggs educational design model on reminding, learning, and motivation for academic achievement in the experimental sciences course", Barzegar and AliAbadi (2013) showed that the use of Gagne's model in the design of experimental sciences course increases learning and recalling compared to conventional methods. However, there was no significant difference between the two groups regarding the motivation for progress (45). In a research entitled as "The effect of implementing the Internet-based education model based on Gagne's model educational events in the Information Technology course at primary school grade on students' sustainability and academic success", Kutlu and Menzi (2013) concluded that the Internet-based learning environments positively affect learning by using appropriate strategies with a positive effect on the sustainability of success (46). In an article titled as "Using the Larillard-Gagne's model for distance education", Hannon (2002) suggested that Gagne and Briggs model can be used in distance learning. This model allows students to achieve learning goals and benefit from a positive learning experience. In a distance learning environment, students expect to receive a quick and distinct feedback of their questions and answers, and the Gagne's model will make this possible (47). Soori (1999) showed in his research that the effect of educational design of education based on Gagne and Briggs model on students' learning is more than the effect of educational design based on the Merrill model and the traditional methods (48).

\section{Computer-assisted Instruction, Virtual Patients, and Human Patient Simulation Based on Gagne's Educational Design Model}

It is very clear that there is no single and coordinated theory in the practical use of educational technology in medicine. Researchers have provided dozens of frameworks and models. Ideally, the effective use of educational technology should begin with classical educational design approaches, learner's needs analysis systematic methods and the development of appropriate training activities. Usually, the analysis design development implementation module (ADDIE) is used to help with organizing and management of educational technology projects. This model includes analysis, design, development, implementation, and evaluation. The design, development, and implementation in this process are far beyond studies in the educational psychology (49, 50). The Gagne's nine educational events form one of the educational design frameworks. According to Gagne, education consists of a set of events that are external to the learner and are designed to support the internal learning processes. Gagne's teaching model, based on Gagne's model, consists of 9 activities. The first 3 activities are based on the fulfillment of the internal conditions and 6 other activities are performed to fulfill the external conditions. Educational events are as activities that the designer designs based on 
Gagne's model after determining its content, order, and sequence to accomplish educational goals. These activities include drawing the attention, learners' awareness of educational objectives, recalling previous knowledge, providing training materials, providing a learning guide, performance testing, providing feedback, performance assessment, encouraging and facilitating the reminding, and transferring data, respectively.

\section{Drawing Attention}

It includes recording the learners' attention with a problem, a case, an instant question or providing interesting and surprising statistics. Hence, they will be involved with learning.

\section{Learners' Awareness of Educational Objectives}

It involves the transfer of expectations to learners by introducing educational goals, considering their colloquial definitions in knowledge, specific skills, or in behaviors that they are expected to acquire them.

\section{Recalling Previous Knowledge}

It involves helping learners build what they are prepared to learn it by reminding their prior knowledge (previous educational materials and individual experiences) that are relevant to current educational materials.

\section{Providing Educational Materials}

It involves the provision of actions or information that is logically organized to prevent the providing of additional information. In the cognitive field, considering the combination of Mayer's principles for the effective use of multimedia, organizing training materials to increase difficulty, and revising the concepts periodically will be useful to facilitate the reminding process.

\section{Providing a Learning Guide}

It involves offering specific guidance to learners on how better understand the concept or gain a skill. Different media and structures should be used to avoid confusion with educational cases.

\section{Performance Testing}

It gives learners plenty of opportunities to apply new knowledge, skills, or behaviors. Frequent practices allow learners to record their perceptions.

\section{Providing Feedback}

It involves providing a proactive, constructive, and instant feedback for learners based on their performance.

\section{Performance Evaluation}

It involves assessing the learners according to the above learning objectives to find out whether the knowledge, skills, or behavior have been used properly or not?

\section{Encouraging and Facilitating Reminding and Transferring Data}

It involves checking out the educational materials, which gives learners an opportunity to regain new knowledge, skills, and behaviors and provides them with opportunities for further training.

A systematic approach to educational design is highly essential in the effective use of educational technology. Gagne's model can help medical education instructors in instructing communication skills, clinical skills, and skills of taking patient history. It can also be useful in gaining problem-solving skills, acquisition of knowledge, and critical thinking. Table 7 shows how the correct use of principles in three common educational technologies can be effective. Medical education instructors may not be accustomed 
with educational methods such as formal approaches in developing training activities. The educational design is much more important when using educational technology than when face-to-face training is used since learning activities are explicitly planned professionally (27).

\section{Discussion}

Educational technology is widely used in all parts of medical education, including safety and control of the environment to reduce risks to the patients, documenting the behavior of learners, organizing training according to individual and group needs, standardization of education, improvement of decision making, improvement of psychomotor skills, and improving clinical skills (1). The virtual patients tool be developed for diverse aspects of medical and nursing education without the need for students and professors to be present in the same place (2). The advantages of using virtual patients in the medical education environment include efficiency, standardization, easy productivity, interoperability, reducing the workload of training instructor, providing rare educational materials, individualizing learning, providing quick individual training and feedback, improving and enhancing clinical skills in an empirical environment without threat, and learner's autonomy and independence (5). Research shows that an efficient virtual patients simulator can provide opportunities for trial and error; it allows learners not to limit their opportunities to questions and exams (6). It allows them to control a specific time to check all the features of the virtual patient simulator (7). It also allows them to monitor virtual anatomy and physiology changes (8). The human patient simulation provides a unique opportunity for students to apply what they have learned and allows them to practice problem-solving skills and grow their self-confidence by placing in the human patient simulation (9). By simulating medical problems, it allows students to integrate knowledge through experimental learning and optimizing the patient's safety (11).

Educational design based on e-learning is effective in better performance of learning. Modern technologies have created a new path for distance learning, especially e-learning. Paying attention to the educational design of this type of training is one of the most important prerequisites for the successful use and implementation of e-learning (51). Careful selection of educational strategies, goals, audiences, content, and the ways to fulfill learning are as significant factors in each learning project. Failure in considering each may question the success and effectiveness of the education. An electronic learning system is like a two-way street that designers and technology will have a mutual relationship. Merely having electronic content cannot be the criterion for successful elearning and the occurrence of learning; but how to use these contents and how to presented them to learners are fundamental factors, which an e-learning designer should consider them (52).

Gagne's model is one of the most famous educational design models based on a systematic approach. This model is derived from cognitive psychology, which can be used both at micro and macro levels for educational design (53). Gagne's educational design model is one of the cognitive-oriented theory models, which works in teaching critical thinking, clinical thinking, selfcentered learning, and, consequently, in lifelong learning better than behaviorism and constructivism approaches. Hannon (2002) suggests that a Gagne's model leads the learners achieving learning goals and gain a 
positive learning experience (47). Gagne's model can help medical education instructors in teaching communication skills, clinical skills, and skills of taking patient's history. It can also be useful in gaining problem-solving skills, acquisition of knowledge, and critical thinking (43).

This research showed that the use of Gagne's educational design model can be associated with better learning due to the following features:

- View, order and regular steps

- Determining the hierarchy and sequencing of activities and learning strategies

- Attention to internal and external educational situations

- Characteristic of increasing learning and the role that the prior knowledge has in this process

- Attention to how to keep and organize information in mind and its order and sequence

- Emphasis on the structure, organization, order and sequence of information to facilitate its processing

- Creating a learning environment where learners can link their prior knowledge with new information

- Providing feedback (developmental and diagnostic) with an approach to improve content

- The use of pre-organizing strategies for linking the course details and the transferring strategy of reminding for new situations

\section{Conclusion}

Eventually, based on the results, one can conclude that computer-assisted instruction, virtual patients, and human patient simulation based on Gagne's educational design model can help medical educators to train communication skills, clinical skills, and patient history taking skills. They can also appear useful in gaining problem-solving skills, acquiring knowledge, and critical thinking with a systematic approach. By considering their advantages and disadvantages, medical instructors can choose the most suitable educational technologies in teaching medical science aimed at achieving the preplanned goals. They help the educational designer in the field of medical education to adopt the best education model of virtual patients based on Mayer's educational media principles and the simulation-based learning education theories commensurate with the goals and content of medical training courses.

\section{Acknowledgements}

Not applicable

\section{Declarations}

Funding source(s)

Not applicable

Ethics approvals and consent to participate Not applicable

\section{Conflict of interest}

We declare that we have no financial or nonfinancial conflicts of interest related to the subject matter or materials discussed in the article. 


\section{References}

1. Harirchi I, Khosravi A, Shariat M, Yunesian M. study impact of virtual patients in surgical training medical students and health science magazine Shahrood University of Medical Sciences. Spring2007; 3 (1). (Persian)

2. Lehmann $\mathrm{R}$.An innovative blended learning approach using virtual patients as preparation for skills laboratory training: perceptions of students and tutors. Lehmann et al. BMC Medical Education 2013; 13: 23.

3. Monika S, Klemenc-Ketis Z. Enhancing primary care clerkships with virtual patients. Journal Education for Primary Car. 2016; 27 (6): 451-454.

4. Salminen H, Zary N, Björklund K. Virtual Patients in Primary Care: Developing a Reusable Model That Fosters Reflective Practice and Clinical Reasoning. Journal of Medical Internet Research. 2014; 16 (1).

5. Horstmann M, Blended E-learning in a Webbased Virtual Hospital: A Useful Tool for Undergraduate Education in Urology, Education for Health. 2013; 22 (2).

6. Adeline M, Deladisma, Medical Student Satisfaction Using a Virtual Patient System to Learn History- Taking and Communication Skills, Association for Surgical Education Annual Meeting (2007), Washington, DC.

7. Amy L.Seybert "Human Patient Simulation in a Pharmacotherapy Course "American Journal of Pharmaceutical Education, 2008; 9: 37-72.

8. Cameron K MacGougan "Human Patient Simulation and Distance Education: A Review Israeli. Journal of Emergency Medicine.2005; 5.

9. Issenberg SB, Mc Gaghie WC, Petrusa ER, Lee Gordon D, Scalese RJ. Features and uses of highfidelity medical simulations that lead to effective learning: a BEME systematic review. 2005. Medical Teacher. 2005; 27 (1): 10-28.

10. Salminen H, Zary N, Björklund K. Virtual Patients in Primary Care: Developing a Reusable Model That Fosters Reflective Practice and Clinical Reasoning. Journal of Medical Internet Research. 2014; 16 (1).
11. Kamin C, Souza K, Heestand D, Moses A, O'Sullivan P. Educational Technology Infrastructure and Services in North American Medical Schools. Academic Medicine. 2006; 81:632-637.

12. Cook D. The ResearchWe Still Are Not Doing: An Agenda for the Study of ComputerBased Learning. Academic Medicine. 2005; 80: 541-548

13. Cendan J. The use of virtual patients in medical school curricula. Adv Physiol Educ. 2012; 36: 48-53. doi:10.1152/advan.00054.2011

14. Pinto A, Selvaggi S, Sicignano G, Vollono, E, Iervolino, L, Amato, F, et al. E-learning tools for education: regulatory aspects, current applications in radiology and future prospects. Radiologia Medica (Torino) 2008; 113 (1): 144-157.

15. Scars brook A. F, Graham R. N, Perriss R. W. Radiology education: a glimpse into the future. Clinical Radiology, 2006; 61(8): 640-648.

16. Weller J, Robinson B, Larsen P, Caldwell C. Simulation-based training to improve acute care skills in medical undergraduates. New Zealand Medical Journal. 2004; 117 (1204): U1119.

17. Cook D.A, Triola M.M. Virtual patients: a critical literature review and proposed next steps. Medical Education. 2009; 43 (4): 303-311.

18. Cook DA, Erwin PJ, Riola MM. Computerized virtual patients in health professions education: systematic review and Meta-analysis. Academic Medicine. 2010; 85: 1589- 1602 .

19. Zary N, Johnson G, and Fors U. Web-based Virtual Patients in Dentistry: Factors influencing the use of cases in the Web-SP system, European J of Dental Education. 2009; 13(2).

20. Monique O, Jabbur-Lopes. Virtual Patients in Pharmacy Education. American Journal of Pharmaceutical Education. 2012; 76 (5): Article 92.

21. Saleh N. The Value of Virtual Patients in Medical Education. Annals of Behavioral Science and Medical Education. 2010; 16 (2): 29-31.

22. James B. Designing, Developing implementing Branched-Narrative Virtual Patients for Medical Education Training and 
Assessment.2010, McGee MD University of Pittsburgh school of Medicine.

23. Veronikas S. An Interview with Richard Mayer. Educational Psychology Review. 2005; 17: $179-189$.

24. Zielke M. Game-Based Virtual PatientsEducational Opportunities and Design Challenges. Interservice, 2010, Industry Training, Simulation, and Education Conference (I/ITSEC).

25. Kidd Erry T. and Song, Holim. Handbook of research on systems and technology. USA: Information Science Reference.

26. Hofmann J. Blended Learning Instructional Design: A Modern Approach, South African Journal Of Business. 2014; 41 (2): 29-38.

27. Gibbons A. S, Boling E, Smith K. M. Instructional design models. In M. Spector, M.2013.

28. Gibbons A. S. An architectural approach to instructional design. New York: Routledge.2013.

29. Lu L. Digital Native Preservice Teachers: Growing Up with Technology, Not Growing up Learning with Technology. Paper to be presented at the Association forEducational Communications and Technology (AECT) annual conference, Jacksonville, FL. Journal of Computer- Based Instruction. 2014; 16 (1): 1-10.

30. Bilton, J.What is Design? http://atschool.eduweb.co.uk/trinity/watdes.html, 2005.

31. Gustafson L, Branch M. "What is instructional design "; University of Georgia, Chapter 2, Retrieved from: http://create.alt.ed.nyu.edu/courses/2174/reading/s mith_ragan_1_2.pdf. 2001; 17-22.

32. Chen R. Instructional Design Methodologies. University of Houston-Downtown, USA IGI Global. 2008; 1-14.

33. Ng JY .Combining Peyton's four-step approach and Gagne's instructional model in teaching slit-lamp examination. Perspect Med Educ. 2004; 3 (6): 480-485.
34. Watson S.L, Reigeluth C.M. The learnercentered paradigm of education. Educational Technology. 2008; 48 (5): 42-48.

35. Merrill D. Components of Instruction toward a Theorical Tool for Instructional Design. Instructional Science in Press, Retrieved from: www.id2.usu.edu.2001; 1-23.

36. Reigeluth C.M, Keller J.B. Understanding instruction. In C. M. Reigeluth \& A. CarrChellman (Eds.), Instructional-Design Theories and Models, 2009, Volume III: Building a Common Knowledge Base. New York: Routledge.

37. Keller J. M. Motivational design for learning and Performance: the ARCS model approach. USA: Springer. 2010.

38. Henich R. Instructional media and technologies for learning. New York: Macmillan Publishing Company.1999.

39. Morrison, Gary. R. Ross, Steven. I. Camp, Gerald A. Designing effective instruction (Fourth Edition) translations Gholam Hossein Rahimi friend. Ahwaz Chamran University Press martyr. 2008.

40. Siemens, George. Handbook of emerging technologies for learning. USA (It is available online at www.knowingnowledge.com), 2010.

41. Galvis AT, Ishee JH. A Comparison of Computer-Assisted Instruction and Traditional Classroom Lecture to Introduce the Occupational Adaptation Theory. The Internet Journal of Allied Health Sciences and Practice. 2011; 9 (3): 1-6.

42. Sternberger C, Meyer L. Hypermedia-assisted instruction: authoring with learning guidelines. Comput Nurs. 2001; 19(2): 69-74.

43. Khadjooi K, Rostami K, Ishaq S. How to use Gagne's model of instructional design in teaching psychomotor skills. Research Institute for Gastroenterology and Liver Diseases, 2011; 4 (3):116-119.

44. Ozmen R. G, Unal H. Comparing the effectiveness and efficiency of Two Methods of teaching Geometric Shape Concepts to Students with Mental Retardation. Educational Sciences: Theory \& Practice. 2008; 8 (2): 669-680. 
45. Barzegar R, Ali Abadi K. The effect of instructional design model Gagne and Briggs on learning and achievement motivation reminders and experimental science. Journal of the curriculum. 2013; 11. (Persian)

46. Kutlu M. O, Menzi N. The Effect of Implementation of Internet-Based Teaching Model Considers Gagne's instructional Events Model in Information Technology Course for Primary (Elementary) Education to Academic Success and Retention. International Journal of Humanities and Social Science. 2013; 18 (3).

47. Hannon P. Gagne and Lorillard's Models of Instruction Applied to Distance Education. International Review of Research in Open and Distance Learning. 2003; 2(3).

48. Surrey M. Compare instructional design patterns learning school science books in Region 3 Karaj. Master's thesis, University of Allameh Tabatabai .2008 (Persian)

49. Pakpoor Y. Instructional technology context. First Edition, Tehran: Didar Publishing Company, spring 2011 (Persian)

50. Strickland AW. ADDIE. Idaho State University College of Education Science, Math \& Technology Education. Retrieved June 29, 2006, from http://ed.isu.edu/addie/index.html

51. Graham M, Scarborough H. Enhancing the learning environment for distance education students. Distance Educ. 2001; 22 (2): 232-44.

52. Swan K, Shih LF. On the nature and development of social presence in online course discussions. J Asynchronous Learn Netw. 2005; 9 (3):115-36.

53. Razavi A. Modern issues in Educational Technology. Ahvaz Chamran University. 2011 (Persian)

\section{How to cite:}

Torbatinezhad H, Amani H. Computer-Assisted Instruction (CAI), Virtual Patients (VP), and Human Patient Simulation (HPS) in Medical Education Based on Gagne's Educational Design Pattern. Jorjani Biomedicine Journal. 2018; 6(2): 1-21. DOI: 10.29252/jorjanibiomedj.6.2.1 